[OR 4.31, 95\%CI 2.-.7, p < 0.0001). Of the $2365(14.87 \%)$ polyps $-0 \mathrm{~mm}$ in size, $4(0.17 \%)$ had adenocarcinoma [OR $41.5,95 \%$ CI $2.2-71, \mathrm{p}=0.01]$

\begin{tabular}{|c|c|c|c|c|}
\hline Size & $\begin{array}{l}\text { Proportion } \\
\%\end{array}$ & Morphology(\%) & Dysplasia (\%) & Odds Ratio \\
\hline $\begin{array}{l}<5 \mathrm{~mm} \\
(\mathrm{~N}=10775)\end{array}$ & 67.74 & $\begin{array}{l}\text { Pedunculated. } \\
\text { Nonpedunculated } \\
3.796 .3\end{array}$ & $\begin{array}{l}\text { No dysplasia. LGD. HGD. } \\
\text { Cancer 34.0. 65.40. } 0.60 \text {. } \\
0.0\end{array}$ & \\
\hline $\begin{array}{l}-0 \mathrm{~mm} \\
(\mathrm{~N}=2365)\end{array}$ & 14.87 & 31.7568 .25 & 21.3374 .444 .060 .17 & $\begin{array}{l}41.5 \\
(p=0.01)\end{array}$ \\
\hline $\begin{array}{l}1-0 \mathrm{~mm} \\
(\mathrm{~N}=1793)\end{array}$ & 11.27 & 46.953 .1 & 12.268 .8915 .673 .25 & $\begin{array}{l}813 \\
(p<0.0001)\end{array}$ \\
\hline $\begin{array}{l}>30 \mathrm{~mm} \\
(\mathrm{~N}=973)\end{array}$ & 6.12 & 14.0885 .92 & 10.169 .50 16.10. 4.30 & $\begin{array}{l}952 \\
(p<0.0001)\end{array}$ \\
\hline
\end{tabular}

Conclusions This study demonstrates that the prevalence of covert cancer in colorectal lesions between $-0 \mathrm{~mm}$ is very low. Cancer risk, however, increased more than 20 fold in polyps greater than $1 \mathrm{~cm} \quad(3.6 \%) \quad[\mathrm{OR} \quad 21, \quad 95 \% \mathrm{CI} \quad 7.8-8.15$ $\mathrm{p}<0.0001]$ Based on the above data, we can conclude that the 'resect and discard' strategy can be extended to colorectal lesions $-0 \mathrm{~mm}$ in size.

\section{PWE-040 CANCERS IN COLONIC POLYPS: SIZE MATTERS}

${ }^{1} \mathrm{E}$ Hossain*, ${ }^{2} \mathrm{P}$ Bhandari, ${ }^{2} \mathrm{~S}$ Arndtz, ${ }^{2} \mathrm{M}$ Abdelrahim. 'Queen Alexandra Hospital, Portsmouth, UK; ${ }^{2} Q A$ Hospital, Portsmouth

\subsection{6/gutjnl-2019-BSGAbstracts.364}

Introduction Colorectal polyps with overt endoscopic features of invasive cancer are referred for surgery. However, polyps without overt features might still harbour cancer. We aim to identify incidence of such covert cancers in colorectal polyps to see if the 'resect and discard' strategy could be extended beyond diminutive polyps.

Methods We analysed outcomes of all patients who were colonoscoped by 5 expert (BCSP) endoscopists between January 2007 to December 2018 and were found to have polyps. Data was prospectively collected on an online endoscopy reporting system and pathology reporting system. A chart review was then carried out analysing the site, size, morphology and histological diagnoses of each polyp.

Results A total of 15906 polyps were removed at colonoscopy over the specified period. Mean size was $7.3 \mathrm{~mm}$ (range: 1 to $120 \mathrm{~mm}) .86 .6 \%$ of all polyps were non pedunculated and $56.3 \%$ polyps were located in the left colon and rectum. The size, site, morphology and histology of these polyps is shown in table 1.

A histopathological diagnosis of polyp cancer was made in $104 / 15906$ polyps $(0.65 \%)$. 94/104 polyp cancers $(90.25 \%)$ were associated with non pedunculated morphology [OR 1.45, 95\% CI 0.7-.78].

No cancer was found in polyps $<5 \mathrm{~mm}$ in size. However, the cancer incidence was $4 / 2365(0.17 \%)$ in polyps $-0 \mathrm{~mm}$,
$58 / 1793(3.25 \%)$, in polyps $1-0 \mathrm{~mm}$ and $42 / 973(4.30 \%)$ in polyps $>30 \mathrm{~mm}$ in size.

89 cancers were found in the left colon and rectum compared with 15 cancers in the right colon ( $85.5 \%$ vs $14.5 \%$ ) [OR 4.31, 95\%CI 2.-.7]. All 4 cancers found in the $-0 \mathrm{~mm}$ category were non-pedunculated polyps in left colon.

\begin{tabular}{|c|c|c|c|c|}
\hline Size & $\begin{array}{l}\text { Proportion } \\
\%\end{array}$ & $\begin{array}{l}\text { Morphology } \\
(\%)\end{array}$ & Location (\%) & Dysplasia (\%) \\
\hline $\begin{array}{l}<5 \mathrm{~mm} \\
(\mathrm{~N}=10775)\end{array}$ & 67.74 & $\begin{array}{l}P * N P * 3.7 \\
96.3\end{array}$ & $\begin{array}{l}\text { Right Left } \\
\text { colon colon } \\
\text { 50.3. } 49.7\end{array}$ & $\begin{array}{l}\text { None LGD. HGD. Cancer } 34.0 \text {. } \\
65.40 .0 .600 .0\end{array}$ \\
\hline $\begin{array}{l}-0 \mathrm{~mm} \\
(\mathrm{~N}=2365)\end{array}$ & 14.87 & $\begin{array}{l}31.75 \\
68.25\end{array}$ & 30.869 .2 & 21.3374 .444 .060 .17 \\
\hline $\begin{array}{l}1-0 \mathrm{~mm} \\
(\mathrm{~N}=1793)\end{array}$ & 11.27 & 46.953 .1 & 31.069 .0 & 12.268 .8915 .673 .25 \\
\hline $\begin{array}{l}>30 \mathrm{~mm} \\
(\mathrm{~N}=973)\end{array}$ & 6.12 & 14.085 .92 & 24.076 .0 & 10.169 .5016 .10 .4 .30 \\
\hline
\end{tabular}

Conclusion We have demonstrated that the prevalence of covert cancer in colorectal lesions $<5 \mathrm{~mm}$ is negligible and that of polyps $-0 \mathrm{~mm}$ is very low $(0.17 \%)$. All these cancers were in non-pedunculated polyps in left colon. This will be a very important information in consideration of Resect \& Discard strategy for polyps $-0 \mathrm{~mm}$ in size.

Cancer risk, however, increased more than 20 fold in polyps between - cm (3.25\%) and 25 fold in polyps $>3 \mathrm{~cm}$ (4.3\%). This calls for careful resection (preferably en-bloc) and retrieval of these polyps to obtain all prognostic information.

\section{PWE-041 RETROSPECTIVE STUDY OF PATIENTS WITH MICROSCOPIC COLITIS}

Ruridh Allen*, Gordon Reid, Santosh Salunke. NHS Forth Valley, Larbert, UK

\subsection{6/gutjnl-2019-BSGAbstracts.365}

Background Microscopic colitis (MC) in its 2 histologically distinct patterns - Lymphocytic Colitis (LC) and Collagenous Colitis (CC) - is an increasingly common cause of non-bloody diarrhoea. There appears to be an association with other autoimmune conditions and a number of culprit medications such as selective serotonin reuptake inhibitors (SSRI) and proton pump inhibitors (PPI). There appears tobe a variability in patient journey from referral to treatment.

Aim We looked to assess the current referral process, demographics and management of patients with MC within Forth Valley Royal Hospital (FVRH).

Method We performed a retrospective analysis of all patients with histologically proven MC from December 2016-December 2017 in FVRH. Data was obtained from pathology reports and patient details, including all clinical data was collected using 'clinical portal'.

Findings In total data was collected from 55 patients, 41 of these were female, with a median age of 65.36 patients had LC, 15 CC and 4 patients had a mixed or unclear diagnosis. 